\title{
A AVALIAÇÃO INSTITUCIONAL NAS UNIVERSIDADES FEDERAIS E AS COMISSÕES PRÓPRIAS DE AVALIAÇÃO
}

\author{
Maria do Carmo de Lacerda Peixoto*
}

Recebido em: 15 de setembro de 2008

Aprovado em: 23 de novembro de 2008

* Doutora em Educação, professora da Universidade Federal de Minas Gerais. E-mail: mcarmo@ufmg.br.

\begin{abstract}
Resumo: A autora analisa as possibilidades que a avaliação institucional, como instrumento para sua formulação de políticas visando aprimorar a gestão, oferece para as universidades federais. Tendo em vista as especificidades dessas instituições, busca avaliar os limites e as perspectivas que elas encontram na realização do modelo de avaliação institucional do SINAES, em que as Comissões Próprias de Avaliação - CPAs se constituem num organismo de grande importância. Por meio de dados qualitativos e quantitativos são analisados, principalmente, aspectos relativos à composição dessas comissões e ao lugar que elas ocupam na estrutura das universidades federais.
\end{abstract}

Palavras chave: Avaliação institucional. SINAES. Universidades federais. Gestão universitária. Planejamento.

\section{INSTITUTIONAL EVALUATION IN THE FEDERAL UNIVERSITIES AND THE INTERNAL EVALUATION COMMITTEES}

\begin{abstract}
The author analyzes the possibilities that institutional evaluation, as an instrument in the formulation of policies to improve the administrative procedures, offers to federal universities. Considering specific characteristics of these institutions, she evaluates their limits and perspectives in the institutional evaluation model of SINAES, of which the Internal Evaluation Committees (CPAs) are a very important part. Mainly aspects relative to the composition of these committees and their place in the structure of the federal universities are analyzed through the use of qualitative and quantitative data.
\end{abstract}

Key words: Institutional evaluation. SINAES. Federal universities. University administration. Planning.

\section{Introdução}

A avaliação da educação superior brasileira adquiriu novas feições com a aprovação da Lei $\mathrm{N}^{\circ}$.10.861, de 14 de abril de 2004, que instituiu o Sistema Nacional de Avaliação da Educação Superior - Sinaes. Entre as alterações introduzidas destaca-se a avaliação institucional - AI, procedida em duas etapas: auto-avaliação e avaliação externa. A primeira dessas etapas já foi concluída, não havendo ainda definição precisa quanto à realização da avaliação externa. 
A análise dos componentes desse processo é importante, pelas contribuições que pode trazer para o conhecimento sobre a avaliação da educação superior brasileira, bem como para a construção de práticas avaliativas. Entre esses componentes podem ser ressaltados: o grau em que a cultura de avaliação já se constituiu nas instituições de ensino superior - IES; as diferenças que a sua categoria administrativa e sua organização acadêmica introduzem nesse processo; as metodologias adotadas para a realização da auto-avaliação.

Nessa análise, as instituições federais de ensino superior - IFES podem se constituir num conjunto especial. Além de se fazerem presentes em todos os estados da federação, a universidade é sua forma de organização acadêmica majoritária e suas instituições têm aportado contribuição importante à produção de conhecimentos e de tecnologias para o País. Além disso, a qualificação do seu corpo de docentes e pesquisadores pode levá-los a mobilizar os setores acadêmico-científicos, em âmbito nacional, para produzir uma reflexão sobre os paradigmas teóricos e epistemológicos da avaliação, contribuindo para os avanços na construção dessa atividade. A essas razões devem ser acrescidas as características próprias da gestão das universidades federais, entre as quais precisa ser considerado o vínculo com o MEC e a prática da administração colegiada. Nesse conjunto de instituições, entre os aspectos a serem analisados ressaltam os documentos que regulam o funcionamento de sua Comissão Própria de Avaliação - CPA; dos procedimentos adotados para estabelecer a composição das CPAs; das metodologias e dos instrumentos propostos e utilizados para realizar a auto-avaliação bem como os relatórios dela resultantes.

O objetivo deste artigo é analisar a avaliação institucional nas universidades federais, considerando suas possibilidades como mecanismo para a formulação de políticas visando ao aprimoramento da gestão dessas IES. O foco da análise está dirigido para a CPA, instância responsável, por lei, pela condução desse processo, considerando os dados relativos à sua composição e à sua inserção na estrutura dessas instituições. Com esses procedimentos pretende-se avaliar o significado, para as universidades federais, desse modelo de realização da atividade de avaliação, que tem a Comissão Própria de Avaliação como instrumento. Inicialmente serão abordadas brevemente as concepções de avaliação vigentes no Brasil, e situada a avaliação institucional no contexto do Sinaes, considerações a que se seguirão a análise da composição e da localização das CPAs no conjunto das IFES, discutindo-se o papel por elas desempenhado. 


\section{A Avaliação como Campo de Disputas}

As mudanças ocorridas na estrutura social, nos aspectos geopolíticos e econômicos, na organização do trabalho e nos papéis dos Estados nacionais a partir de meados de 1970, produziram, entre outras conseqüências, o deslocamento da educação superior para o centro dos debates e da formulação de políticas para o desenvolvimento econômico e social. O papel ocupado por essa educação na sociedade contemporânea, tendo em vista sua relação com o mundo do trabalho e o mercado; sua contribuição para o desenvolvimento econômico e social; seu modelo de produção de conhecimento fundado na pesquisa em grandes laboratórios e que demanda fortes investimentos estatais, em contraposição à perspectiva neoliberal do Estado Mínimo; a qualidade da oferta do seu ensino, são alguns dos temas desse debate.

A expansão de matrículas nos sistemas de educação superior que ocorreu em vários países a partir da década de 1960, resultou, para alguns deles, na disseminação de instituições de ensino que atuam em condições inadequadas de infra-estrutura e recursos humanos, e cujos projetos curriculares nem sempre atendem às demandas apresentadas pelo processo acelerado de produção e difusão do conhecimento. Nessas circunstâncias, a busca por programas e/ou sistemas avaliativos capazes de mensurar o trabalho e a eficácia das instituições de ensino superior, como forma de legitimar os recursos nelas aplicados e de redirecionar os investimentos, estão entre os temas que ocuparam as agendas da maior parte dos países a partir de então.

No Brasil, o modo desordenado como se deu a expansão do sistema de educação superior no final do século XX, chamou a atenção dos gestores e formuladores de políticas para a necessidade da aplicação de instrumentos de avaliação, destinados a assegurar níveis de qualidade capazes de corresponder às demandas de formação profissional e de atender a critérios científicos e acadêmicos reconhecidos internacionalmente. Nesse contexto, vão se confrontar duas concepções de avaliação. Uma, de base quantitativa, enfatizando a mensuração de desempenhos e resultados, com o estabelecimento de uma hierarquia entre as IES e voltada principalmente para a supervisão do funcionamento institucional. E outra, de base qualitativa, buscando compreender e atribuir significados aos processos e atividades acadêmicas, e identificar formas para superar fragilidades e desenvolver potencialidades.

O debate e a prática da avaliação institucional se instalaram divididos entre essas duas perspectivas, tendo como vetores a responsabilidade das instituições de ensino superior na prestação de contas à sociedade e a orientação para o 
aperfeiçoamento permanente no cumprimento de suas funções. Assistiu-se, de um lado, ao predomínio do controle da qualidade referenciado pelo desempenho e eficiência do sistema de educação superior e, de outro, pelo exercício da avaliação como prática construída coletivamente e orientada para a produção da qualidade, a melhoria institucional e a formação dos agentes da educação superior.

Essas perspectivas distintas se sustentam por concepções também dissimiles acerca do papel da educação superior, como partes de um conflito de posições políticas. Nesse conflito, a busca de hegemonia e de produção de resultados ultrapassa a área da avaliação propriamente dita, sendo mais que uma simples confrontação teórica ou meramente acadêmica de grupos em disputa pela hegemonia de uma semântica ${ }^{1}$. Na realidade, "é uma importante questão política, que tem interesse público, porque produz fortes e substantivas implicações no sistema educativo e, portanto, na sociedade” (DIAS SOBRINHO, 1999, p. 62). Essa contraposição de concepções caracteriza a avaliação da educação superior como um campo político, um "lugar em que se geram, na concorrência entre agentes [...] produtos políticos, problemas, programas, análises, comentários, conceitos, acontecimentos, entre os quais os cidadãos comuns, reduzidos ao estatuto de 'consumidores' devem escolher” (BOURDIEU, 1989, p. 164). Para esse autor, por isso não é incomum que se configure a tendência desse campo se organizar em torno da oposição entre dois pólos.

Esse confronto se concretiza na educação superior brasileira em dois momentos principais. Na vigência da Lei Nº. 9.131, de 24 de novembro de 1995 e da legislação posterior, a ênfase da avaliação, centrada na dimensão do ensino, recaía nos resultados focalizando produtividade, eficiência, prestação de contas, e controle do desempenho frente a um padrão estabelecido. O conceito de avaliação foi reduzido, desse modo, às dimensões de supervisão e controle, com base em um processo externo de verificação de cursos e instituições, desenvolvido sem articulação com os processos institucionais internos.

Seguiu-se a aprovação da Lei No 10.861 que instituiu o Sinaes, em 2004, e que representou um ponto de inflexão na política de avaliação da educação superior brasileira. Seu objetivo era a construção de um sistema nacional de avaliação da educação superior que articulasse a regulação e a avaliação educativa, esta última mais formativa e voltada para a atribuição de juízos de valor e mérito, tendo em vista o incremento da qualidade e as capacidades de emancipação.

1 Para Dias Sobrinho (1999), o fato de não ser a avaliação institucional uma área de conhecimentos e de ações práticas consolidada, contribuiu para que ela tenha se constituído como um campo de contendas e em intensa disputa. 
Nessa perspectiva, a avaliação institucional não seria um fim em si mesma, mas parte de um conjunto de políticas públicas da educação superior voltadas para a expansão do sistema por meio da democratização do acesso, e para uma qualificação que é parte de um processo mais amplo de revalorização da educação superior, dentro de um projeto de desenvolvimento da nação (SINAES, 2007, p. 24-27). Para atingir um maior grau de realização da responsabilidade social e científica das instituições e da educação superior, esse sistema busca "incorporar aos processos avaliativos todos os agentes, todas as dimensões e instâncias das instituições, respeitados os papéis específicos dos participantes, a identidade e a missão de cada uma delas.” (SINAES, 2007, p. 98)

Enquanto política educacional, a avaliação dos resultados da aplicação dessa lei ainda precisa ser objeto de uma análise aprofundada, o que escapa aos propósitos desse artigo. Não deixa de chamar a atenção, no entanto, a ênfase que a supervisão e a regulação têm recebido dos organismos responsáveis em período recente. Manifestações diversas e em diferentes oportunidades têm ocorrido como reação a esta tendência, sem ainda uma sinalização concreta de alteração. A permanência dessa orientação pode comprometer o alcance dos objetivos que foram propostos quando foi formulada a política em questão, e merece ser considerada de modo mais acurado no debate e gestão do tema.

\section{A Avaliação Institucional no SINAES}

A avaliação institucional é o processo que envolve o esforço da instituição em se conhecer e ser conhecida por outros setores da sociedade e que, articulada ao planejamento, tem grande potencial para contribuir na gestão estratégica (TRIGUEIRO, 2004). Para a Comissão Nacional de Avaliação da Educação Superior - Conaes, a avaliação da instituição é aquela que visa a IES como uma totalidade integrada, buscando identificar o grau de coerência que há entre sua missão e as políticas institucionais efetivamente realizadas. A ênfase na auto-avaliação e na sua prática educativa tem por objetivo gerar nos membros da comunidade acadêmica a autoconsciência de sua qualidade, de seus problemas e de desafios, por meio de mecanismos institucionalizados e participativos de realização (MEC/CONAES, 2004). Por essa razão, a Conaes entende que ela deve ser realizada como um processo cíclico, criativo e renovador de análise e síntese das dimensões da IES, permitindo a re-análise das prioridades estabelecidas no projeto político institucional e o engajamento da comunidade acadêmica na construção de novas alternativas e práticas. Na medida em que se torna uma atividade permanente, a AI pode ser instrumento 
de construção e/ou consolidação de uma cultura de avaliação, com a qual a comunidade interna se identifique e se comprometa.

Conforme regula a legislação do Sinaes, as instituições deveriam constituir Comissão Própria de Avaliação - CPA, responsável pela condução dos processos internos de avaliação e pela sistematização e prestação de informações aos órgãos do sistema. $\mathrm{O}$ artigo 11 da Lei $\mathrm{N}^{\circ}$. 10.861/04 estabelece que a composição dessa comissão deva contemplar todos os segmentos da comunidade acadêmica bem como membros da sociedade civil organizada, deixando a critério dos órgãos colegiados superiores das instituições a definição do modo de organização, quantidade de membros e dinâmica de funcionamento, tendo em vista as características da IES, seu porte e a existência de experiências anteriores de avaliação. Um acréscimo importante foi feito pela Conaes nas suas diretrizes, ao explicitar que a CPA deve ser reconhecida como "órgão de representação acadêmica e não da administração da instituição.” (MEC/CONAES, 2004, p. 19)

\section{A Constituição das CPAS: Aspectos Descritivos}

Em conseqüência do grau de liberdade que a legislação atribuiu às IES para a organização das CPAs, presume-se que existam modelos distintos de composição e funcionamento dessas comissões. Nesse sentido, a diversidade das características que esse processo assume nas IFES pode ser um elemento importante para a análise do papel desempenhado pelas comissões nessa avaliação. Como procedimento analítico, inicialmente será feita a descrição da constituição dessas comissões nas IES em geral para, a seguir, aprofundar essa análise sobre as comissões das IFES, abrangendo, também, seu funcionamento.

\section{A composição das CPAs nas instituições de ensino superior}

Dando cumprimento ao estabelecido na legislação que disciplinou o Sinaes, as instituições de ensino superior compuseram suas CPAs. Almeida Jr. (2005) analisou os procedimentos adotados pelo INEP para formar os coordenadores das CPAs nos seminários regionais, e traçou o perfil desses coordenadores a partir da consulta aos dados do cadastro eletrônico de comissões que foi feito pelas IES até o mês de dezembro de 2004. Nessa ocasião, já estavam cadastradas 1.831 CPAs, compreendendo a cerca de $84 \%$ das instituições brasileiras. O percentual de IES sem comissões cadastradas (16\%), segundo o autor, corresponde àquelas de credenciamento recente e às vinculadas aos sistemas 
estaduais que, até aquele momento, não haviam firmado acordo de cooperação para se integrarem ao Sinaes.

O perfil dos coordenadores das comissões apresentado pelo autor permite observar que $50 \%$ deles eram de instituições públicas e que desses, $50 \%$ eram das IFES. No conjunto das IES, 62\% eram docentes, 36\% servidores técnicoadministrativos, $1,4 \%$ membros da sociedade civil e 3\% discentes. Quanto à qualificação, $42 \%$ eram mestres e $15 \%$ doutores. Considerando o grupo das universidades, o cenário é um pouco distinto. 82\% dos coordenadores das CPAs, são docentes e $18 \%$ são técnico-administrativos. Quanto à qualificação, $42 \%$ têm o título de mestre e $40 \%$ o de doutor, percentual que, no primeiro caso, é igual ao encontrado para o conjunto das instituições e, no segundo caso, é significativamente mais elevado.

Mesmo ressalvado o fato de que a legislação não estabeleceu nenhum critério específico quanto à organização dessas comissões, dois aspectos dessa descrição merecem destaque, tendo em vista os objetivos propostos para a avaliação institucional. O primeiro deles, é o fato de que percentual superior a $4 \%$ das CPAs é coordenada por membros externos às IES ou por estudantes, componentes que, em comparação com o dos docentes e dos servidores técnico-administrativos, têm graus de responsabilidade distintos em relação à gestão da instituição.

Que razões teriam levado a que essas IES adotassem tais decisões? No caso dos membros externos, é possível supor que a atribuição da coordenação a eles tenha se dado porque essas pessoas teriam competências técnicas específicas na área de avaliação. Cabe perguntar, no entanto, se este argumento seria suficiente para justificar a entrega da liderança do processo a quem não é membro da instituição, e cujas possibilidades são restritas de buscar e obter articulações futuras entre a auto-avaliação e o planejamento na IES.

No caso dos estudantes, por sua vez, é possível supor tratar-se de alunos mais idosos e que talvez tenham tido experiência anterior com a área de avaliação. Ao contrário do que ocorre com os docentes e os técnico-administrativos, no entanto, sua presença é transitória na instituição, o que torna sua situação similar à dos membros externos quanto às condições para conduzir as atividades de avaliação e a articulação entre avaliação e planejamento. Deve ser observado que a atribuição a esses componentes da CPA da responsabilidade pela coordenação, contudo, escapa aos cânones que predominam numa instituição de ensino superior, e indicam que, onde ela ocorreu, haveria uma compreensão inadequada tanto do papel dessa comissão, como da auto-avaliação e do próprio processo de avaliação. 
O segundo aspecto diz respeito à qualificação dos coordenadores, não podendo ser considerado uma surpresa o fato de que a maioria deles seja constituída por mestres, dado que a maior parte das IES brasileiras é privada. Além disso, como a universidade não é a sua forma de organização predominante, e há menor rigor nas exigências legais quanto à qualificação docente para as formas de organização acadêmica não universitárias, esse resultado corresponde ao que delas se poderia esperar. Ao mesmo tempo, como a maior parte das universidades cumpre com as regras definidas na Lei de Diretrizes e Bases relativas à composição do corpo docente: $1 / 3$ com doutorado e $1 / 3$ em tempo integral, fica também explicado o equilíbrio existente entre mestres e doutores vigente entre os coordenadores das suas CPAs.

Ao fazer uso da autonomia facultada pela Lei $\mathrm{N}^{\circ}$. 10.861/04 para compor e organizar a CPA, pode-se considerar que um pequeno percentual das IES não tomou a si, de fato, a responsabilidade que lhes cabia em relação à atividade de avaliação, no que concerne aos impactos da mesma sobre a vida futura da instituição. Os dados disponíveis infelizmente não permitem avançar mais na análise dessa questão, já que não é possível identificar se foi apenas nas IES privadas que as CPAs têm estudantes e por membros externos como coordenadores, ou se isto ocorreu também nas instituições públicas e, nesse caso, a que instância administrativa estas pertencem. Dada a não existência de acesso público às informações sobre a composição das CPAs, não é possível proceder, nesse momento, a uma análise mais aprofundada da questão.

\section{A Comissão Própria de Avaliação nas Instituições Federais de Ensino Superior}

Antes de analisar a constituição das CPAs das IFES, faço uma breve apresentação dessas instituições, destacando o papel que elas desempenham na educação superior brasileira. Foi a partir de 4 de dezembro de 1950 que algumas universidades passaram a compor o conjunto que hoje se denomina instituições federais de ensino superior. Nesta data foi aprovada a Lei $\mathrm{N}^{\circ}$. 1.254 que dispôs sobre o "sistema federal de ensino superior supletivo dos sistemas estaduais", integrado por estabelecimentos mantidos pela União, pelos poderes públicos locais e por entidades de caráter privado. Por esse dispositivo compuseram esse sistema as então assim denominadas Universidade do Brasil, Universidade de Minas Gerais, Universidade do Recife, Universidade da Bahia, Universidade do Paraná e Universidade do Rio Grande do Sul. Pelo artigo $2^{\circ}$ dessa lei, esses estabelecimentos seriam, gradativamente, incluídos na categoria de mantidos pela União, "atendendo-se à eficiência do seu funcionamento por prazo não 
inferior a 20 anos, ao número avultado de seus alunos e à sua projeção nos meios culturais como centros unificadores do pensamento científico brasileiro".

O atual conjunto das IFES é composto por 58 instituições: uma faculdade, quatro centros de educação tecnológica (Cefets) e 53 universidades, localizadas estas últimas em todos os estados da federação e no Distrito Federal, numa composição que vem sendo ampliada de forma mais expressiva desde 2005. Atuando em todas as áreas do conhecimento, essas instituições desempenham papel importante na indução do desenvolvimento econômico, social e cultural do País. Nelas, estudam número superior a 600 mil alunos de graduação e pósgraduação, além dos estudantes de ensino fundamental e médio que freqüentam seus colégios de aplicação e escolas técnicas e agrícolas. As IFES formam profissionais qualificados, produzem pesquisas, desenvolvem tecnologias, e realizam diversas atividades para a superação das desigualdades regionais.

Com relação à experiência dessas instituições com a avaliação, no trabalho em que sintetizou os resultados de seu estudo sobre a avaliação institucional, realizada no âmbito do Programa de Avaliação Institucional das Universidades Brasileiras - Paiub em 23 universidades públicas e privadas e implementada especialmente na graduação, Trigueiro (1999) observou que, nas instituições públicas, as maiores resistências para operar as mudanças propostas por essa avaliação foram as encontradas nas universidades federais. Foi nelas também, no entanto, onde ocorreram as experiências mais significativas de produção do conhecimento sobre o tema e entre as metodologias que foram aplicadas. Em estudo posterior (TRIGUEIRO, 2003) o mesmo autor aponta que são as IFES de maior porte que melhor conduzem o processo de avaliação institucional do ponto de vista técnico, mas são elas também que estão mais distantes de compatibilizá-lo com um projeto global de planejamento, de tomada de decisão e de correção de rumos institucionais.

\section{A coleta dos dados}

O sistema nacional de avaliação não dispõe de mecanismos destinados a fornecer aos pesquisadores as informações relativas aos procedimentos e resultados do processo de avaliação como, por exemplo, sobre a organização e composição das CPAs, os relatórios de auto-avaliação institucional, e outros. Por essa razão, os dados sobre as comissões das IFES que serão aqui analisados foram buscados nas páginas na internet de cada uma delas² . A adoção desse

2 Uma primeira busca foi feita na primeira quinzena de outubro de 2007, seguida de outra, na segunda quinzena de março de 2008, tendo sido constatadas algumas alterações nos dados em relação ao cenário 
procedimento tem conseqüências para o tratamento dos dados, pois não foi possível localizar informações de todas as comissões, dado que nem sempre os registros sobre a avaliação institucional estão disponíveis nos sites. A análise a seguir compreende os dados de 55 IFES, das quais quatro são Cefets, uma é faculdade e 47 são universidades. Como essas últimas são um percentual bastante representativo do total (85\%) e apenas as informações de três universidades não foram localizadas, a descrição da organização e composição das comissões feita a seguir abrange o conjunto das CPAs das universidades federais.

\section{A composição das CPAs das IFES}

A busca feita nas páginas da internet permitiu verificar que, em alguns casos, as comissões foram integradas por subcomissões organizadas ora por áreas do conhecimento, ora por unidades acadêmicas, ora segundo os temas propostos pelo roteiro de auto-avaliação elaborado pela Conaes. Escapa ao objetivo deste estudo, contudo, analisar as estratégias adotadas pelas IFES ou pelas CPAs para realizar o trabalho de auto-avaliação. Por esse motivo, serão consideradas aqui apenas as informações que concernem à comissão principal.

Em alguns casos, quando se confronta o documento legal que instituiu a CPA com a informação posteriormente registrada no relatório de auto-avaliação ${ }^{3}$, os números de membros das comissões não são coincidentes, ora sendo superiores ora inferiores ao que constava por ocasião da sua constituição oficial. Nas IFES onde isso ocorreu, optou-se por considerar a composição que consta no relatório, porque esse registro pode ser compreendido sendo o daquelas pessoas que efetivamente participaram de todo processo de avaliação.

Uma primeira observação é de que, considerando o conjunto das IFES, o número médio de integrantes das CPAs é elevado e, à exceção da região Centro Oeste, ele não apresenta diferenças significativas entre as regiões do País, como mostra a TABELA 1.

Os dados dessa tabela mostram que, apesar da média de integrantes ser bastante aproximado, a dispersão é grande quando se consideram os números mínimo e máximo de membros. O total de componentes varia de 5 a 33, pertencendo o menor valor às CPAs das Universidades Federais da Paraíba e do Rio de Janeiro, e o maior à da Universidade Federal de Pernambuco. Conforme já mencionado, as comissões de algumas IFES foram integradas por subcomissões, o que permite formular a hipótese de que sob número tão elevado de membros

anterior. Agradeço a colaboração de Patrícia Sallum para a realização da primeira dessas etapas.

3 Este relatório não está disponível nos sites de todas as CPAs. 
da comissão da UFPE estivesse a intenção de, posteriormente, reorganizá-la, promovendo a divisão de tarefas mas sem chegar a formalizar subcomissões. Há ainda outros três casos em que o número de membros é elevado: nas CPAs da Universidade Federal do Triângulo Mineiro e da Universidade de Brasília, ambas com 22 componentes, e a da Universidade Federal de Uberlândia, com 20 membros, podendo a elas ser também aplicada a hipótese anterior. Uma análise dos procedimentos metodológicos utilizados por essas CPAs para realizar a auto-avaliação pode ser uma forma de confirmar se se tratou, ou não, de um caso de divisão de trabalho, mas isso extrapola a abrangência do que aqui se pretende tratar.

TABELA 1 - Número médio de membros das Comissões Próprias de Avaliação das IFES, por região, considerando a maior e a menor composição.

\begin{tabular}{|l|c|c|c|c|}
\hline Região & IFES pesquisadas & Número médio & \multicolumn{2}{|l|}{ Número de membros } \\
\cline { 4 - 5 } & por região & de integrantes & Mínimo & \multicolumn{2}{l|}{ Máximo } \\
\hline Norte & 8 & 11,6 & 9 & 13 \\
\hline Nordeste & 15 & 11,6 & 5 & 33 \\
\hline Centro Oeste & 5 & 15 & 9 & 22 \\
\hline Sudeste & 19 & 11,6 & 5 & 22 \\
\hline Sul & 8 & 10,5 & 5 & 17 \\
\hline IFES & 55 & 11,7 & 5 & 33 \\
\hline
\end{tabular}

Essa composição com número de membros elevado, entre outros aspectos, pode ter contribuído para tornar mais complexo o trabalho da comissão. Como mais de $60 \%$ das CPAs analisadas têm mais de 10 componentes, é possível supor que a auto-avaliação enfrentou algum grau de dificuldade quanto à realização das reuniões. Tendo em vista que o quorum necessário para reunir os componentes nesses casos é de seis integrantes no mínimo, o trabalho dessas comissões certamente não foi realizado sem percalços. Esse número mais elevado, contudo, pode ter trazido também uma contribuição importante para o processo de auto-avaliação, enriquecendo-o com a convivência de percepções e concepções diversas sobre o tema e sobre a IES.

Outro aspecto a destacar diz respeito ao que foi estabelecido pelo artigo 11 da Lei $N^{\circ}$. 10.861/04, com relação à obrigação de que as CPAs devam ser integradas por todos os segmentos da comunidade acadêmica e pela sociedade civil organizada. Em sete das IFES pesquisadas, contudo, não houve indicação do membro da sociedade civil, e em quatro delas estão ausentes os estudantes. 
O mesmo artigo veda uma composição da comissão que privilegie a maioria absoluta de um dos segmentos, diretriz que também não foi cumprida em todas as IFES, pois em várias das CPAs o número de docentes é bem superior ao dos demais. Enquanto os números mínimo e máximo de participação de professores nas comissões variam de 1 a 12, essa relação entre os servidores técnico-administrativos é de 1 a 6 , entre os discentes de 0 a 8 , e entre os membros externos de 0 a 5 . Essas relações tão distintas permitem supor que nem todas as IFES respeitaram o equilíbrio exigido pela lei. Dois exemplos mais extremos reforçam esta suposição: na Universidade Federal de Rondônia a proporção de docentes em relação à dos demais segmentos corresponde a $75 \%$ do conjunto de membros da CPA, e na Universidade Federal de Uberlândia ela corresponde a 50\% dos membros. A análise dos relatórios de auto-avaliação poderá indicar em que medida isso teria prejudicado o resultado final do trabalho da comissão.

\section{A localização da CPA na estrutura das IFES}

Aspecto importante a considerar se refere à diretriz da Conaes de que a CPA é um órgão de representação acadêmica e não da administração da instituição. Ao formular essa diretriz, certamente a comissão nacional buscava assegurar a autonomia da CPA frente à administração da IES e, ao mesmo tempo, afirmar seu papel como acadêmico e não meramente administrativo. Esses objetivos se justificavam, entre outros aspectos, pelo fato de que em muitas instituições privadas a administração central é personalizada no proprietário, e de que a atuação das mantenedoras nelas se faz presente de modo muito mais direto na definição das ações. Nessas circunstâncias, era preciso assegurar a autonomia das CPAs, não sendo desejável, por isso, que ela mantivesse vínculos com a administração central da IES.

Esse não é, certamente, o caso quando se trata das instituições federais de ensino superior. Talvez seja por essa razão que a informação disponível nas páginas da internet para as comissões de 71\% das IFES (39), dê conta de que, em várias delas, a CPA está situada formalmente na estrutura da instituição, e que 20 outras estão vinculadas ao gabinete do Reitor. Apenas duas entre as 39 analisadas constam como comissão sem qualquer vínculo explícito com a estrutura administrativa da IES. Quatro CPAs estão ligadas mais diretamente à administração, sendo três constituídas como órgãos suplementares e uma como órgão de assessoria. Outras 13 estão vinculadas a Pró-Reitorias, sendo 10 ligadas à área do Planejamento, três à da Graduação, e uma à Secretaria de Avaliação Institucional. 
Tendo em vista esta distribuição, cabe perguntar se o caráter dessas comissões teria se alterado em relação ao que a Conaes pretendeu com essa diretriz, nos casos em que se configurou um elo específico delas com a administração central. Teriam elas perdido em autonomia durante a realização da auto-avaliação? É mais provável que essa localização tenha sido apenas uma solução encontrada pelas IFES para assegurar o suporte administrativo de que a CPA iria necessitar para seu trabalho ${ }^{4}$. A importância da inserção efetiva da avaliação institucional nas IFES justifica que algumas implicações dessa questão sejam abordadas ainda mais adiante nesse artigo.

É digno de nota ainda, o vínculo que três IFES mantêm com as Pró-Reitorias de Graduação, o que é um indicador da presença do mesmo entendimento da avaliação institucional que predominou na vigência do Paiub, restrita aos cursos de graduação. Pode-se supor que nas IFES onde este vínculo foi definido está sendo preservada a compreensão da avaliação institucional como ação de interesse específico do ensino de graduação e não da instituição no seu conjunto e nas suas inter-relações. Essa opção pode se constituir, talvez, num obstáculo para o desenvolvimento posterior, nessas IES, dos objetivos da avaliação institucional de uma forma mais completa.

$\mathrm{O}$ fato de que, em algumas universidades, as CPAs têm um lugar próprio na estrutura administrativa como órgão suplementar, como órgão de assessoria ou fazendo parte da Secretaria de Avaliação Institucional, indica a presença de uma percepção distinta do papel da avaliação institucional por parte da administração dessas IES. Esse aspecto será um pouco mais explorado no item a seguir, observando algumas considerações em torno de parâmetros inerentes à avaliação institucional.

\section{Perspectivas para a Avaliação Institucional nas Universidades Federais}

A idéia de que as instituições de ensino superior devam atribuir à avaliação institucional um grau elevado de importância no seu processo de gestão, tem estado presente na construção dos sistemas avaliativos que vêm sendo propostos para a educação superior brasileira. A exigência de que as IES constituam Comissões Próprias de Avaliação é um passo adiante nessa proposição, por representar a explicitação de que essa atividade tenha um lócus próprio no in-

4 No regimento da comissão da Universidade Federal de Santa Catarina, por exemplo, foi definida a vinculação da CPA a uma pró-reitoria, com a finalidade de assegurar o suporte administrativo. Este vínculo foi formalizado, mais tarde, com a Pró-Reitoria de Graduação, conforme consta do $\S 2^{\circ}$ do art. $1^{\circ}$ do Regimento da Comissão Própria de Avaliação da UFSC, anexo à Resolução nº. 013/CUn, de 07 de junho de 2005. 
terior das instituições. Considerando o grau diferenciado com que a relevância da AI é contemplada pelas IES, dois aspectos podem ser destacados. O primeiro é proveniente dos membros da comunidade universitária, e diz respeito ao grau em que ela está sensibilizada para esta atividade e para as conseqüências que ela traz para o processo decisório das IES. O segundo é proveniente dos gestores das instituições, e diz respeito ao lugar que foi definido para a CPA na estrutura da administração central. Esses dois aspectos serão comentados a seguir.

Analisando os desafios enfrentados pelas CPAs, Andriola (2005) destaca a importância da sensibilização da comunidade interna e do incentivo à mobilização dos atores institucionais para participar do processo. Para enfrentar esses desafios, o autor recomenda aumentar o grau de informação presente na instituição sobre a sistemática avaliativa e sobre o paradigma teórico que a fundamenta, e também a necessidade de dar fim ao que ele chama de mito da avaliação como sinônimo de punição e de estabelecimento de rankings. Quando a AI é bem sucedida, diz Andriola, a disseminação de informações sobre a instituição é um elemento que contribui para aumentar a consciência políticoinstitucional da comunidade interna, e também para aumentar as cobranças relacionadas à aplicação de medidas de aperfeiçoamento. O resultado, segundo ele, é a elevação da consciência da comunidade interna sobre a importância da avaliação, o estímulo ao seu engajamento nos debates para buscar soluções inovadoras, e a facilitação da formulação e execução do planejamento, tornando, assim, a gestão mais eficaz.

Cabe observar que a disseminação das informações sobre a avaliação e sobre o seu paradigma teórico não é desafio de fácil enfrentamento, principalmente considerando que, para que essa disseminação seja bem sucedida, é preciso pessoas interessadas nas informações caso contrário o impacto dessa ação pode ser irrelevante no conjunto do processo. Uma demonstração da coerência dessa afirmação é encontrada no trabalho de Assis e Oliveira (2007). Em pesquisa que visou a análise das repercussões das políticas de avaliação, nas instituições de ensino superior privadas de Goiás, sobre a prática pedagógica dos professores, os autores declararam-se surpresos com o fato de que cerca de $70 \%$ dos docentes aparentaram desconhecer a proposta do Sinaes. Afirmam eles que não seria de se esperar o nível de desinformação demonstrado por professores e alunos sobre os exames nacionais, os seus princípios, fundamentos e estratégias, sendo eles como são, os sujeitos do processo de ensino-aprendizagem.

Tendo em vista a diversidade do corpo docente que integra as universidades federais, pode-se arriscar a suposição de que nelas esse cenário não seria muito distinto. Da mesma forma em que há docentes, servidores técnico-administra- 
tivos e alunos bastante envolvidos e comprometidos com os rumos que estão sendo dados à instituição, há outros que não querem se envolver com as questões institucionais, tendo por objetivo em relação a IES apenas usufruir as condições que ela proporciona para a realização de seus projetos pessoais. Este retrato da diversidade presente na composição das universidades federais caracteriza também grande parte das instituições públicas. Se isso assim é, torna-se mais complexa a tarefa de corresponder de forma adequada aos desafios mencionados por Andriola tendo em vista atingir os benefícios por eles proporcionados.

Um outro aspecto pode ser ainda destacado na comparação entre as instituições públicas e privadas. Na pesquisa já mencionada, Trigueiro observou mais agilidade e flexibilidade das IES privadas do que nas públicas na condução da avaliação, fato que, segundo ele, poderia ser explicado em razão de as primeiras terem uma estrutura organizacional mais leve e seus proprietários atuarem de forma mais explícita quanto à direção que querem ver impressa a essa atividade, inclusive no que concerne ao aproveitamento dos resultados. (TRIGUEIRO, 1999)

Esse o registro é mais bem compreendido tendo em vista as características do processo decisório vigente na maior parte das IES públicas, onde predomina o modo de gestão colegiada. Nelas, a participação dos diversos segmentos na tomada de decisão torna a gestão mais democrática. Pela mesma razão, no entanto, isso torna o processo decisório mais lento, resultando em um menor grau de previsibilidade quanto às soluções que serão adotadas. Esses fatos explicam porque a agilidade é menor na definição das decisões sobre a avaliação em relação às IES privadas, e a primazia de uma tendência mais cautelosa e conservadora, por isso mesmo menos propensa a aprovar mudanças de forma rápida nas instituições públicas.

O mesmo autor registra que as atividades ligadas à avaliação em diversas IES estavam localizadas nas pró-reitorias de planejamento, afirmando ser difícil perceber até que ponto se estabeleceu nessas instituições uma relação dinâmica entre avaliação e planejamento ou se as duas instâncias funcionavam como ambientes institucionais separados. Para ele, o vínculo existente é mais restrito às possibilidades que a área de planejamento oferece para o uso dos dados disponíveis, de modo a ter acesso às informações necessárias para a análise da instituição, e ao suporte administrativo e de infra-estrutura física disponibilizado por aquela área.

Os dados encontrados no presente estudo contribuem para reforçar essa percepção, pois nas 39 CPAs onde foi possível identificar o vínculo institucional, $26 \%$ estão ligadas às pró-reitorias de planejamento. É provável que, tendo em 
vista o estágio inicial em que se encontra a construção da avaliação institucional nas IFES, se e onde essa relação dinâmica ocorre como planejado a implantação dessa relação, nessas IES ainda está nas suas etapas preliminares.

A consideração dos parâmetros aqui apresentados sugere alguns questionamentos sobre a necessidade de que a avaliação institucional se constitua de modo permanente nas IFES. Essa necessidade é reforçada pela relevância de que realizar a AI é parte da responsabilidade institucional e deve ocorrer independente, até mesmo, da existência de prescrições legais.

O primeiro questionamento diz respeito ao papel desempenhado pela CPA, conforme o tipo de instituição que está sendo avaliada. $O$ fato de ser a categoria administrativa da IES pública ou privada pode exigir o estabelecimento de tipos distintos de demandas do papel da comissão? A distinção presente no interior das instituições públicas - federal, estadual e municipal - também deveria ser considerada nesse caso? E quanto à organização acadêmica, seria desejável que a atuação da CPA de uma universidade fosse similar a de uma faculdade? É possível esperar homogeneidade de uma comissão que atua em campos tão diversificados?

O segundo grupo de questionamentos diz respeito ao vínculo institucional da CPA. Em que medida a responsabilidade pela condução de um processo avaliativo numa universidade federal, que se pretende venha a ser permanente, pode ser atribuída a uma comissão que não mantém nenhuma ligação com a administração central dessa IES? É possível que, pelo fato de a CPA ocupar um lugar específico na estrutura administrativa de uma IFES, ela venha a ter sua autonomia comprometida? A ligação dessa comissão à administração central da instituição de ensino superior resultaria também na perda do caráter acadêmico que se deseja caracterize sua atuação?

Nem todas essas questões podem ser plenamente respondidas no âmbito deste artigo, mas as possibilidades de articular avaliação, supervisão e planejamento são maiores, ao meu ver, naquelas IFES que optaram por implantar a CPA como órgão suplementar e de assessoria porque seu grau de interação com os demais órgãos da hierarquia institucional é mais elevado.

Além disso, quatro universidades federais encontraram soluções distintas na abordagem da questão institucional, duas delas em fase mais adiantada de implementação. Para sistematizar a AI de forma permanente, coordenando e articulando suas ações, a Universidade Federal do Rio Grande do Sul constituiu, no ano de 2000, a Secretaria de Avaliação Institucional. Quando da sua criação, a CPA passou a integrar a secretaria sendo que, no organograma desse órgão a comissão está representada em ordem hierárquica superior. Em 2002, 
a Universidade Federal de Minas Gerais ${ }^{5}$ instituiu a Diretoria de Avaliação Institucional também como órgão da administração central, com o objetivo de coordenar as ações de avaliação naquela IES. A CPA, criada em 2004, não é vinculada à diretoria, desfrutando, por intermédio desta, do suporte administrativo necessário e de condições organizacionais e da interação que a diretoria mantém com as demais instâncias da gestão da universidade, situação que é, talvez, similar à encontrada na Ufrgs. Em ambas as universidades a CPA é responsável pela avaliação institucional no interior do ciclo avaliativo do Sinaes. As competências tanto da secretaria como da diretoria, contudo, são de caráter mais abrangente, envolvendo a abordagem das questões institucionais por meio de, por exemplo, a realização de estudos e atividades relacionadas à gestão das informações.

Na Universidade Federal do Rio Grande, por sua vez, foi criada, em 2005, a Secretaria de Avaliação Institucional, vinculada à Pró-Reitoria de Planejamento, em conseqüência do estudo que a CPA produziu quando elaborou o projeto para realizar a auto-avaliação. Essa secretaria tem também o objetivo de tornar a avaliação institucional um processo permanente na universidade, e os papéis da comissão e da secretaria são complementares. Na pesquisa feita na página da Universidade Federal de Campina Grande, finalmente, há referência a experiência similar, embora não estejam disponíveis maiores informações sobre o seu funcionamento. Consta desse registro que a Coordenação de Avaliação Institucional, junto com a CPA, é responsável por coordenar o processo de auto-avaliação institucional e pelo acompanhamento dos processos de avaliação externa.

Essas alternativas de abordagem da questão avaliativa expressam a vontade e o compromisso de algumas IES em atribuir caráter permanente à atividade, articulando o trabalho da CPA com o de um outro organismo voltado especificamente para o campo da avaliação institucional. Alternativas como essas parecem ser capazes de proporcionar soluções mais efetivas para a realização da AI. Em relação à CPA, esses organismos apresentam algumas vantagens como, por exemplo, o fato de poderem ordenar despesas, o que lhes assegura maior autonomia para conceber e realizar seus estudos. Além disso, por estarem situados na administração central, as posições ocupadas por seus dirigentes são equivalentes às dos responsáveis pelos demais órgãos da hierarquia institucional. Desse modo, podem desfrutar, em melhores condições das oportunidades de promover a articulação com as outras instâncias da gestão da IFES para a

5 Este registro está sendo feito principalmente a partir do conhecimento que a autora tem da UFMG, pois nem todas estas informações estão disponíveis na página da universidade na internet. 
realização do seu trabalho, bem como para construir condições favoráveis no sentido de que os resultados do seu trabalho de avaliação se articulem com o planejamento e se convertam em políticas institucionais.

\section{Conclusão}

Nesse artigo foram expostas algumas especificidades da avaliação institucional das IES brasileiras, processo que se encontra ainda em sua fase inicial, e envolve, entre as etapas exigidas pelo Sinaes, apenas a da auto-avaliação. As características por meio das quais esse processo está se realizando são bastante diversificadas e, nas universidades federais, além do número médio de membros das CPAs ser elevado, há várias IFES que não obedeceram ao que prescreve a legislação em relação à sua composição. Além disso, a diversificação do vínculo institucional dessas comissões nas instituições federais demonstra a necessidade de uma melhor explicitação acerca de como essas IES compreendem o papel a ser desempenhado pela AI.

A análise das características assumidas pelas CPAs na sua composição, por sua vez, permite identificar alguns pontos a serem aprofundados posteriormente. Entre outros aspectos, devem ser analisadas as metodologias que foram utilizadas por essas comissões para realizar o trabalho de auto-avaliação, o papel que as distinções entre IES públicas e privadas desempenha no trabalho das CPAs, além da abordagem, com maior grau de detalhe, de alguns dos aspectos analisados por meio da realização de entrevistas com coordenadores e membros dessas comissões.

As experiências de inserção da avaliação institucional na estrutura da administração central em vigor em algumas IFES, sinalizam para a construção de um tratamento da questão que visa assegurar sua realização de forma mais dinâmica e permanente do que aquela restrita aos ciclos avaliativos do Sinaes. Essas iniciativas evidenciam um grau mais elevado de sensibilidade política por parte das reitorias dessas IFES em relação à área, inclusive no que diz respeito à possibilidade de incrementar sua interação com o planejamento. Um dos componentes de maior relevância do processo de avaliação institucional é, sem dúvida, a importância a ela atribuída pelo gestor da instituição, seja pública ou privada, em relação aos resultados das avaliações.

Questões como a demora em divulgar, mobilizar e tornar públicos os resultados da avaliação, a ausência de mecanismos ágeis para realizar as mudanças identificadas, e a falta de clareza quanto ao papel da AI, estão relacionadas ao baixo grau de institucionalização da avaliação nas universidades federais, e têm 
potencial para comprometer o êxito do processo. Não é possível desconsiderar, também, a instabilidade histórica que caracteriza as políticas brasileiras, as educacionais em especial. Nesse caso, o risco de descontinuidade que essa trajetória recém-iniciada corre não pode ser desconsiderado, nem de que venha a sofrer alterações significativas. A conjugação desses aspectos pode resultar no enfraquecimento do processo avaliativo, como instrumento para estabelecer um efetivo programa para o aprimoramento da qualidade nas universidades federais.

Aspecto adicional a considerar são os dois grandes desafios com que essas universidades se defrontam na atualidade, e aos quais precisam responder sem que se produzam alterações substanciais no elevado padrão de qualidade que tem sido a marca da sua atuação. A intensificação de demandas para que ofereçam cursos na modalidade de educação a distância como a Universidade Aberta do Brasil, e o seu comprometimento com as metas do Projeto Reestruturação e Expansão das Universidades Federais - Reuni, exigem mais ainda de uma avaliação institucional permanente. Bem conduzida e articulada ao planejamento, seu papel será de grande relevância nesse processo.

\section{Referências}

ALMEIDA JR., Vicente. O processo de implementação das Comissões Próprias de Avaliação (CPAs): ações desenvolvidas e perfil dos coordenadores. In: RISTOFF, Dilvo; ALMEIDA JR., Vicente (Orgs). Avaliação participativa, perspectivas e desafios. Brasília: INEP, 2005. p. 39-56.

ANDRIOLA, Wagner B. Desafios e necessidades que se apresentam às Comissões Próprias de Avaliação (CPAs) das instituições de ensino superior visando à implementação do Sistema Nacional de Avaliação da Educação Superior (SINAES). In: RISTOFF, Dilvo; ALMEIDA JR., Vicente (Orgs). Avaliação participativa, perspectivas e desafios. Brasília: INEP, 2005. p. 57-70.

ASSIS, Lúcia M. de; OLIVEIRA, João F. Repercussões das políticas públicas para a avaliação das IES na prática pedagógica de professores em instituições privadas. Avaliação, Campinas, v.12, n. 1, p. 111-131, mar. 2007.

BOURDIEU, Pierre. O poder simbólico. Lisboa: Difel, 1989. 
DIAS SOBRINHO, José. Avaliação e privatização do ensino superior. In: TRINDADE, Hélgio (Org), Universidade em ruínas na república dos professores. Petrópolis: Vozes, 1999. p. 61-72.

MEC/CONAES. Diretrizes para a avaliação das instituições de educação superior. Brasília, 2004.

SINAES. Sistema Nacional de Avaliação da Educação Superior: da concepção à regulamentação. 4. ed. ampl. Brasília: INEP, 2007.

TRIGUEIRO, Michelangelo G. S. Universidades públicas, desafios e possibilidades no Brasil contemporâneo. Brasília: EdUnB, 1999.

. Reforma universitária e mudanças no ensino superior no Brasil, Observatorio de la Educación Superior en América Latina y el Caribe, Brasília, 2003. Disponível em <http:www.iesalc.unesco.org.ve>. Acesso em: 30 jul.2007.

. A avaliação institucional e a redefinição das estruturas e modelos de gestão das instituições de ensino superior do país. Avaliação, Campinas, v. 9, n. 3, p 11-30, set. 2004. 